\title{
CULTURA, EDUCAÇÃO, DOMINAÇÃO: GRAMSCI, THOMPSON, WILLIAMS
}

\author{
Angela Maria Souza Martins ${ }^{1}$ \\ Lúcia Maria Wanderley Neves ${ }^{2}$
}

\begin{abstract}
RESUMO
Este artigo analisa alguns elementos teóricos do materialismo histórico que fundamentaram a apreensão da dialeticidade entre singularidade e coletividade e entre ser e consciência na análise das práticas culturais contemporâneas, segundo a ótica de Antonio Gramsci, E. P. Thompson e Raymond Williams. Primeiro apresenta-se de modo sucinto as contribuições desses autores quanto à natureza da cultura e da educação. Depois são destacados elementos teóricos do materialismo histórico que contribuíram para superar a visão elitista de cultura, com a intenção de explicitar a natureza da relação entre cultura, educação e dominação, quais sejam: a relação entre e estrutura e superestrutura, objetividade e subjetividade; o conceito de classe social como processo e como relação; e o conceito de hegemonia como estratégia para dominação de classe no capitalismo do século XX. Destaca-se também alguns pontos que contribuem para a discussão sobre o conteúdo e a forma da educação política e escolar no Brasil contemporâneo.

Palavras-chave: cultura, educação, dominação, materialismo histórico, Gramsci, Thompson e Williams.
\end{abstract}

\section{CULTURE, EDUCATION, DOMINATION: GRAMSCI, THOMPSON, WILLIAMS}

\begin{abstract}
This article examines some theoretical elements of historical materialism that justified the seizure of the dialectic between singularity and collectivity, and between being and consciousness in the analysis of contemporary cultural practices, from the viewpoint of Antonio Gramsci, E. P. Thompson and Raymond Williams. First we present succinctly the contributions of these authors as for the nature of culture and education. Are then highlighted theoretical elements of historical materialism that contributed to overcome the elitist culture perspective, with the intention of clarifying the nature of the relationship between culture, education and domination, which are: the relationship between structure and superstructure, objectivity and subjectivity, the concept of social class as a process and as a relation, and the concept of hegemony as a strategy for class domination in twentiethcentury capitalism. We also stand out some points that contribute to the discussion about the content and form of education and school politics in contemporary Brazil.

Keywords: culture, education, domination, historical materialism, Gramsci, Thompson and Williams
\end{abstract}




\section{Introdução}

Este artigo sistematiza mais uma etapa dos estudos por nós desenvolvidos nesses dois últimos anos com vistas a explicitar os pontos de confluência das ideias de Antonio Gramsci, Edward P. Thompson e Raymond Williams em relação à cultura e à educação. $\mathrm{O}$ primeiro resultado, o artigo Materialismo histórico, cultura e educação: Gramsci, Thompson, Williams (2013), teve por objetivo apresentar elementos de um novo olhar sobre o materialismo histórico que permitiram a esses três autores realizarem uma reinterpretação da natureza da cultura e da educação no mundo contemporâneo.

Neste novo trabalho, serão destacados os elementos teóricos que fizeram com que esses autores pudessem construir uma teoria marxista de cultura ${ }^{3}$ que, ao evidenciar a indissociabilidade entre cultura, educação e dominação no capitalismo, oferece novos elementos para a explicação da natureza da cultura e da educação neste século que se inicia.

Duas concepções de cultura são amplamente difundidas na atualidade. A primeira, expressão do senso comum, relaciona cultura à erudição. Nessa acepção conservadora, somente poucos "iluminados" teriam a capacidade de pensar, expressar seus sentimentos e tomar decisões. A educação, limitada ao espaço escolar, teria por finalidade formar as elites intelectuais das diferentes formações sociais. A segunda, com ampla aceitação no debate filosófico e científico contemporâneo, desconsidera as determinações materiais da produção da vida, afirmando a prática cultural como uma dimensão do ser social independente. A educação, como prática cultural, nessa acepção, adaptaria primordialmente os valores caros à natureza humana, às necessidades inerentes às sociedades contemporâneas: sensibilidade, fraternidade, posse e colaboração.

À ideia elitista de cultura como erudição, os três autores, cada um a seu modo, contrapuseram a noção de cultura como algo comum a todos os homens. Ao produzir a sua existência o homem, em relação com os outros homens, produz sua existência material e simbólica. A cultura expressa e é expressão do modo de produção da existência humana em determinado tempo e espaço. Nesse sentido, todos os homens fazem cultura.

A despeito de ser comum a todos, no capitalismo, devido ao caráter de classe das relações sociais, a cultura dominante é a cultura da classe dominante. A educação, em sentido amplo, como educação política e, em sentido estrito, como educação escolar, tem como finalidade majoritária reproduzir os fundamentos e as práticas culturais inerentes às relações de dominação. Entretanto, dependendo da correlação das forças sociais, poderá se constituir também em estratégia de construção da emancipação humana das relações de exploração e de dominação historicamente construídas, oferecendo elementos para a construção de uma cultura emancipadora na qual, pela consciência da dominação, possa construir um novo modo de existência.

À ideia de uma cultura descarnada, imaterial, cara à corrente culturalista do debate contemporâneo sobre cultura, esses três autores, fundamentados na dialeticidade da relação entre estrutura e superestrutura, na natureza indissociável entre objetividade e subjetividade e na unidade contraditória entre o material e o espiritual, contrapõem a noção de cultura como força produtiva, como constituinte e constitutiva das relações de dominação de classe, e, concomitantemente, como elemento propulsor da transformação social. Nessa perspectiva, a revolução cultural torna-se parte constitutiva e constituinte da revolução social.

A educação como prática cultural desempenha, como força produtiva, papel estratégico na conformação aos padrões da sociabilidade dominante e na reprodução ampliada da riqueza nas sociedades urbano-industriais contemporâneas. Como força 
produtiva, a educação pode, também, contribuir para edificar os pilares de uma relação social livre da exploração e da dominação de poucos sobre a maioria.

Ao realçar o caráter de classe das relações culturais, a teoria marxista de cultura, sem invalidar o seu papel fundamental na construção das individualidades e singularidades, demarca os condicionantes sociais dessa construção.

Para o entendimento dessa tripla dimensão da cultura e da educação, como expressão e formação de individualidades, como elemento constitutivo da dominação de classe e como instrumento propulsor da transformação social, Gramsci, Thompson e Williams lançaram um novo olhar sobre o materialismo histórico. Neste artigo, são abordados alguns elementos teóricos do materialismo histórico que fundamentaram a apreensão dessa dialeticidade entre singularidade e coletividade e entre ser e consciência na análise das práticas culturais contemporâneas.

Em um primeiro momento, serão apresentadas sucintamente as contribuições desses autores quanto à natureza da cultura e da educação. Em seguida, serão destacados entre os elementos teóricos do materialismo histórico aqueles que mais contribuíram para a superação de uma visão elitista ou culturalista de cultura e mais efetivamente se prestaram a explicitar a natureza da relação entre cultura, educação e dominação, quais sejam: a relação entre estrutura e superestrutura, que traduz a relação entre objetividade e subjetividade na constituição da historicidade; o conceito de classe social como processo e como relação; e o conceito de hegemonia como estratégia privilegiada de dominação de classe no capitalismo do século XX. Por fim, a título de considerações finais, serão destacados alguns pontos que venham a contribuir para a discussão sobre o conteúdo e a forma da educação política e escolar no Brasil contemporâneo.

\section{Um novo olhar sobre cultura e educação}

As reflexões de Gramsci, Thompson e Williams sobre a cultura e a educação contribuem para entender os movimentos de conservação e transformação das relações sociais contemporâneas, no interior do capitalismo. Tais reflexões evidenciam o quão imprescindível é compreender a cultura e o processo educacional na construção da hegemonia e da contra-hegemonia. Cultura, como modo de vida e expressão dos conhecimentos e das artes, e educação, na dupla acepção de educação política e educação escolar, não podem ser consideradas como processos sociais secundários. Esses três autores lembram, cada um a seu modo, que a produção de ideias, valores, normas e símbolos é uma atividade fundamental do ser humano que contribui para estabelecer relações sociais, instituições e formações.

Gramsci, por exemplo, observa que a cultura é produto de uma complexa elaboração social e que cada classe social tem um modo específico de elaborar a consciência e a cultura. Mais especificamente, a cultura representa um "modo de viver, de pensar e de operar" (GRAMSCI, 1999, p. 258) e implica organização e conquista de consciência. Ao refletir sobre o 'americanismo', nas primeiras décadas do século XX, ele observou, com muita propriedade, que a cultura urbano-industrial estava se consolidando no mundo contemporâneo e buscava a formação de um novo tipo de homem que se adaptasse aos novos sistemas de trabalho e de convivência social. Lembrou também que o capital tem uma função civilizadora, portanto cultura e educação são fundamentais para cumprir esta função. Gramsci procurava entender como a burguesia consolidava suas práticas culturais para manter a hegemonia e também como poderiam ser criados novos caminhos para a construção de um processo contra-hegemônico. 
Mesmo que Gramsci não tenha construído especificamente uma teoria de cultura, suas reflexões sobre as concepções de mundo, vigentes em cada período histórico, nos conduzem a pistas importantes sobre a dimensão econômica e política das práticas culturais e educacionais. Ou seja, "não pode existir quantidade sem qualidade e qualidade sem quantidade (economia sem cultura, atividade prática sem inteligência e vice-versa" (GRAMSCI, 1999, p. 408). Esta reflexão nos remete ao processo educacional no mundo contemporâneo, quando a escolarização precisa se ampliar e estabelecer um novo tipo de qualidade para satisfazer as necessidades da cultura urbano-industrial. Este é um aspecto importante para pensar os novos processos de dominação de classe.

Nos diferentes períodos históricos, cada classe social apresenta suas concepções de mundo, que se expressam na ação. Para tornar-se hegemônica, uma determinada classe social impõe limites às demais concepções existentes por meio de um amplo processo pedagógico, ou seja, ela precisa utilizar estratégias pedagógicas para buscar a adesão das demais classes sociais. No decorrer do século XX, o capitalismo apresentou projetos sociais e políticos que se transformavam de acordo com suas diferentes fases. Em todas elas, cultura e educação foram partes imprescindíveis na produção e reprodução desse modelo societário.

Thompson, assim como Gramsci, reconhece ser a cultura fundamental para a compreensão da complexidade e das contradições sociais no capitalismo contemporâneo. Para ele,

uma cultura é também um conjunto de diferentes recursos, em que há sempre uma troca entre o escrito e o oral, o dominante e o subordinado, a aldeia e a metrópole; é uma arena de elementos conflitivos, que somente sob uma pressão imperiosa - por exemplo, o nacionalismo, a consciência de classe ou a ortodoxia religiosa predominante - assume a forma de um "sistema" (THOMPSON, 2005, p. 17).

Dessa forma, este autor se posiciona contrariamente a formulações sobre a cultura que lhe atribuem um caráter homogêneo e apartado dos conflitos sociais. Ele nos diz que

[...] na verdade o próprio termo "cultura", com sua invocação confortável de um consenso, pode distrair nossa atenção das contradições sociais e culturais, das fraturas e oposições existentes dentro do conjunto (THOMPSON, 2005, p. 17).

Thompson ressalta ainda o aspecto ativo da cultura. Para ele, "o povo faz e refaz sua própria cultura" (THOMPSON, 2001, p. 211). Por isso, tornam-se imprescindíveis, na análise das relações sociais e de trabalho capitalistas, os ritos, os costumes que são passados de geração a geração e modos simbólicos (THOMPSON, 2005).

Associando cultura e experiência, este autor observou que nas relações sociais e de produção os homens vivem experiências que possibilitam a criação de normas, valores, costumes e ideias. Ou seja, homens e mulheres experimentam situações e relações produtivas determinadas "como necessidades e interesses e como antagonismos, e em seguida 'tratam' essa experiência em sua consciência e sua cultura [...] das mais complexas maneiras e [...] agem, por sua vez, sobre a situação determinada" (THOMPSON, 1981, p. 182). Desse modo, Thompson busca compreender como se constrói, na complexidade das determinações históricas, a reciprocidade entre o ser e o pensar. As experiências materiais se transformam em formas culturais e, por isso, 
certos sistemas de valores são consoantes com certos modos de produção e certos modos de produção e relações de produção são inconcebíveis sem sistemas de valores consoantes. Um não depende do outro. Não existe uma ideologia moral pertencente a uma superestrutura, o que existe são duas coisas que constituem as faces da mesma moeda (THOMPSON, 1979, p. 315 apud MATTOS, 2012, p. 86).

Esta reciprocidade entre o ser e o pensar o leva a perceber com clareza que qualquer tarefa revolucionária pressupõe esta dupla e concomitante dimensão. Daí explicitar que

não só o socialismo, mas qualquer futuro feito pelos homens e mulheres não se baseia apenas na "ciência", ou nas determinações da necessidade, mas também numa escolha de valores e nas lutas para tornar efetivas essas escolhas (THOMPSON, 1981, p. 212).

Atribuindo essa dupla dimensão também à educação, Thompson criticou o processo educacional de meados do século $\mathrm{XX}$ e a postura de educadores por não conseguirem distinguir o trabalho educacional do controle social e, assim, estabelecerem estratégias educacionais que desconsideravam a importância e validade das experiências e da cultura de seus alunos. Esta postura gerou uma dicotomia entre cultura letrada e experiência de vida no seio das classes trabalhadoras.

Ele observou também que, com a ampliação das oportunidades educacionais na sociedade industrial, a educação escolar passa a se configurar como "um instrumento de mobilidade social seletiva", um meio eficaz para o sucesso, conseguido pela "recompensa financeira, um certo estilo de vida profissional e um certo prestígio social" (THOMPSON, 2002, p. 42). Aliás, essa postura político-pedagógica torna-se predominante em todo o processo de escolarização contemporâneo até os nossos dias.

Sua proposta educacional, contrapondo-se a essa visão dominante, enfatiza para todos os níveis e modalidades do ensino uma educação emancipadora, baseada na dialética entre educação e experiência. Ao sistematizar a dialética entre educação e experiência na relação educativa, Thompson se aproxima dos princípios educativos gramscianos.

Ao conferir uma importância crucial às práticas humanas para as transformações políticas, econômicas e sociais, Gramsci e Thompson contribuíram de modo significativo para reflexões sobre o processo de formação humana e, consequentemente, sobre o processo educacional nas diferentes instâncias do ser social, bem como, especificamente, na escola.

Williams, por sua vez, ao construir uma teoria materialista da cultura, acrescenta e explicita as contribuições de Gramsci e de Thompson para o entendimento da cultura e da educação. Para ele,

toda sociedade humana tem sua própria forma, seus próprios propósitos, seus próprios significados. Toda sociedade humana expressa tudo isso nas instituições, nas artes e no conhecimento. A formação de uma sociedade é a descoberta de significados e direções comuns e seu desenvolvimento se dá no debate ativo e no seu aperfeiçoamento, sob a pressão da experiência, do contato e das invenções, inscrevendo-se na própria terra. A sociedade em desenvolvimento é um dado, e, no entanto, 
ela se constrói e reconstrói em cada modo de pensar individual. A formação desse modo individual é, a princípio, o lento aprendizado de formas, propósitos e significados de modo a possibilitar o trabalho, a observação e a comunicação (WILLIAMS, 1958, p. 4 apud CEVASCO, 2001, p. 48-49).

Conforme explicitado nesta citação, Williams chama a atenção para o fato de que "a produção de significados e valores é uma atividade humana primária que estrutura as formas, instituições, relações, e também as artes" (CEVASCO, 2001, p. 50).

Se a produção de significados e valores constitui uma atividade primordial dos homens, o processo de socialização é educativo, mesmo porque este autor considera que a socialização não prescinde da aprendizagem de conhecimentos e de habilidades que todos precisam adquirir para se inserir em seu tempo e espaço. Este processo educativo efetiva-se por intermédio de instituições como: a família, as escolas, as igrejas, as comunidades específicas e os locais específicos de trabalho e a mídia (WILLIAMS, 1979). Por isso, as instituições educacionais são imprescindíveis para que a classe dominante passe seus valores, normas e princípios, com o intuito de consolidar sua dominação.

Considerando este aspecto do processo de dominação, Williams afirma que um processo de mudança das forças produtivas e das relações de produção implica mudanças nas forças intelectuais de conhecimento que possibilitam a tomada de decisão consciente, isto porque "a consciência não é mais o mero produto do ser social, mas é ao mesmo tempo uma condição da sua existência prática e, ainda, uma de suas forças produtivas centrais" (WILLIAMS, 2011, p. 349). Assim não podemos fazer mudanças substanciais no interior de uma determinada sociedade sem cuidar dos processos que lidam com as forças intelectuais e morais.

Completando esta reflexão, Williams nos diz que

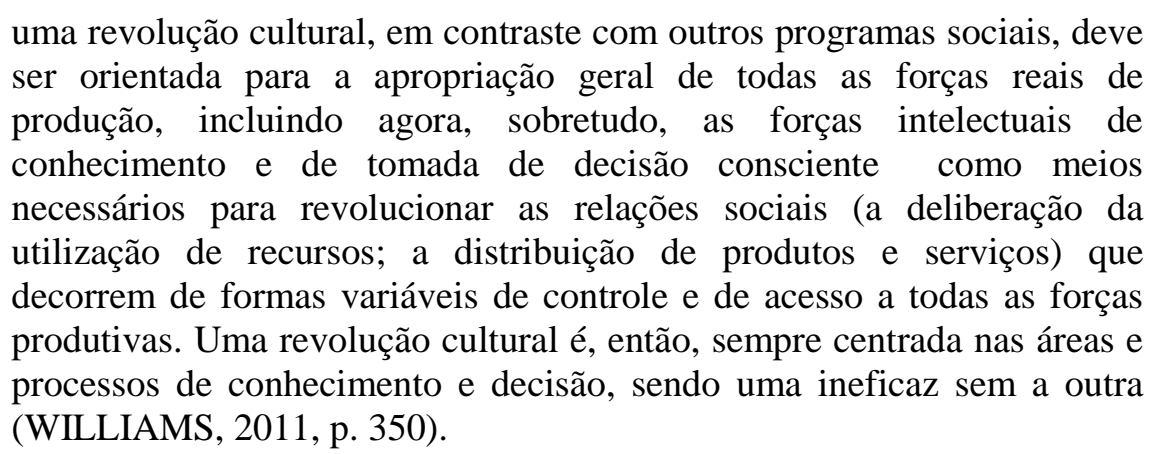

Nesse sentido, o processo de dominação de uma classe se efetiva pelo poder, pela propriedade e pela cultura do vivido, ou seja, a classe dominante cria hábitos, normas, valores e símbolos, um modo de ser que precisa ser mantido. Por isso a cultura e a educação são espaços importantes de luta. Num processo hegemônico, a cultura e a educação são protagonistas que conferem sentido para a consolidação política e econômica da classe dominante, assim como ambas são também imprescindíveis no processo contrahegemônico. Por isso, Williams ressalta que a consolidação de uma cultura comum por meio das escolas, família, igreja e meios de comunicação de massa é uma estratégia importante da classe dominante para efetivar sua hegemonia. Para enfrentar esta hegemonia, ele propõe o acesso igualitário ao processo de escolarização, a redefinição dos conteúdos escolares, o financiamento pela sociedade da produção artística e escolar e a redefinição da lógica capitalista da comunicação de massas. 
Apoiados nas reflexões de Gramsci, Thompson e Williams, podemos afirmar que o estudo da cultura e da educação de uma determinada sociedade contribui para a compreensão dos processos de exploração, subordinação e resistência, bem como para evidenciar os parâmetros que guiam as transformações nas forças produtivas e nas relações sociais de produção.

\section{A relação entre estrutura e superestrutura em Gramsci, Thompson e Williams}

Gramsci, Thompson e Williams resgatam o caráter processual do materialismo dialético ao mostrarem que há uma relação de reciprocidade entre estrutura e superestrutura. Eles destacam que os aspectos simbólicos, morais e intelectuais são importantes para entender as relações econômicas e políticas. A partir desse pressuposto, mostram que as atividades humanas são fundamentais para a compreensão da estrutura e da dinâmica do ser social na sociedade capitalista.

Segundo Gramsci, estrutura e superestrutura formam um bloco histórico, ambas mantêm uma relação de reciprocidade dialética. Existe um nexo vital e necessário entre elas. A estrutura não exerce uma determinação absoluta sobre a superestrutura, pois ambas estão intimamente relacionadas, mesmo porque a superestrutura é "uma realidade [...] objetiva e operante [...] [sendo] o terreno no qual determinados grupos sociais tomam consciência do próprio ser social, da própria força, das próprias tarefas, do próprio devir" (GRAMSCI, 1999, p. 388). Ele alerta que não devemos transformar as relações econômicas num deus oculto, absoluto e pleno que a tudo determina, desconsiderando a dialeticidade de uma realidade sociocultural.

Analisar as relações entre estrutura e superestrutura é crucial para desvendar as forças sociais que atuam num determinado contexto histórico, ou seja, é imprescindível conhecer as ideias, os valores e as práticas que orientam as ações das diferentes classes sociais numa determinada sociedade, uma vez que a realidade social está em movimento e há "uma reação ativa do homem sobre a estrutura" (Gramsci, 1999, p. 370).

É preciso destacar que a complexidade e a dinamicidade das relações sociais e também da relação estrutura e superestrutura somente podem ser percebidas se for considerada a relação ativa e dialética que articula subjetividade e objetividade na composição de um bloco histórico.

Thompson, assim como Gramsci, destaca o entrelaçamento das relações econômicas e não econômicas na sociedade (THOMPSON, 2001). Embora mostre a importância e a centralidade do modo de produção, das relações de poder e propriedade, questiona o entendimento de que o modo de produção se reduz a aspectos econômicos. Thompson observa que não é possível aceitar o reducionismo e o determinismo econômico que frequentemente atribui-se a esta relação, porque estes empobrecem o entendimento da complexidade das relações de produção. Destaca que para se compreender efetivamente como se constitui uma sociedade, precisa-se da agência humana, das experiências travadas no interior das relações sociais. Thompson explica que homens e mulheres são seres racionais que refletem sobre si e o mundo, por isso "não [se pode] conceber nenhuma forma de ser social independentemente de seus conceitos e expectativas organizadores, nem poderia o ser social reproduzir-se por um único dia sem o pensamento" (THOMPSON, 1981, p. 16). A experiência é determinante porque exerce pressões sobre a consciência social, pois "assim como o ser é pensado, também o pensamento é vivido" (THOMPSON, 1981, p. 17).

A relação entre o ser social e a consciência social é fundamental para mostrar que 
há uma organização cognitiva da vida correspondente ao modo de produção e às formações de classe historicamente transcorridas. Esse é o "senso comum" do poder, saturando a vida cotidiana e se expressando mais ou menos conscientemente - na abrangente cúpula de hegemonia da classe dominante e nas suas formas de dominação ideológica.[...] Contudo, no interior e por baixo desse arco, há um sem-número de contextos e situações em que os homens e mulheres, ao se confrontar com as necessidades de sua existência, formulam seus próprios valores e criam sua cultura própria, intrínsecos ao seu modo de vida (THOMPSON, 2001, p. 260-261).

Para compreender a relação de reciprocidade entre estrutura e superestrutura, Thompson diz ser necessário conhecer como são vividas e pensadas as experiências sociais no processo de embate entre as classes sociais, no interior de uma formação social e histórica. "Porque o diálogo entre a consciência e o ser torna-se cada vez mais complexo, [...] quando a consciência crítica está atuando sobre uma matéria-prima feita de seu próprio material: artefatos intelectuais, relações sociais, o fato histórico" (THOMPSON, 1981, p. 27). Ao enfatizar o diálogo entre consciência e ser, e o papel ativo da agência humana, Thompson mostra que a estrutura não é o lugar da primazia do econômico, de onde decorre como reflexo secundário as normas e a cultura, na verdade deve-se enfatizar "a simultaneidade da manifestação de relações produtivas particulares em todos os sistemas e áreas da vida social" (THOMPSON, 2001, p. 254).

Assim como Gramsci e Thompson, Williams questiona a existência de uma estrutura determinante e uma superestrutura determinada e revê o papel da determinação. Williams, no capítulo "Marxismo e cultura", no livro Cultura e sociedade (1969), destaca que Marx, ao refletir sobre a sociedade no século XIX, compreendeu que a organização econômica não devia ser concebida destacada das questões intelectuais e morais. Desse modo, Williams considerava que o uso do modelo base/superestrutura foi utilizado por Marx para combater as versões idealistas e também para restabelecer uma visão de totalidade da organização societária. Williams lembrava que era necessário compreender que a determinação deveria ser vista como um "processo complexo e inter-relacionado de limites e pressões [que] está na própria totalidade do processo social" (WILLIAMS, 1979, p. 91).

Williams mostra que o econômico, o político e o cultural estão inter-relacionados. Há uma unidade qualitativa dessas três dimensões no processo sócio-histórico. Elas se relacionam como um todo, ou seja, expressam um modo de vida de uma sociedade. A estrutura não determina de forma unívoca todos os segmentos de uma sociedade, porque deve-se considerar que nesse processo há uma intervenção importante da ação humana consciente. Tanto Williams como Thompson mostram que não se pode separar pensamento e atividade, consciência e produção material.

A sociedade é "um processo constitutivo com pressões muito poderosas que se expressam em formações políticas, econômicas e culturais e são internalizadas e se tornam "vontades individuais" (WILLIAMS, 1979, p. 91). Nesse sentido, a determinação não deve ser vista como um controle total sobre tudo e todos, porque é a experiência social que estabelece limite e exerce pressões (WILLIAMS, 1979). Além disso, a experiência social instaura a cultura, por isso a cultura não deve ser considerada como algo posterior e secundário a infraestrutura, porque as práticas culturais são forças produtivas, "estas práticas interagem, se relacionam e se combinam de formas complexas" (CEVASCO, 2001, p. 145). 
As reflexões de Williams indicam que, nas sociedades capitalistas, as interações das práticas sociais e o processo de dominação de uma determinada classe sobre outra não se efetivam somente por meio do poder, da propriedade, mas também pela cultura do vivido, a partir de experiências, hábitos, normas, modos de ser que sofrem pressões e são ressignificados de tal modo que as pessoas pensam e sentem de uma determinada forma, se conformando ou se rebelando no interior de uma ordem social.

\section{Classe segundo Gramsci, Thompson e Williams}

Gramsci, Thompson e Williams consideram que a formação de uma classe é um processo histórico, alicerçado nas relações econômicas, nas relações de poder e, concomitantemente, na vivência individual e coletiva das práticas culturais.

Sem desconsiderar o princípio materialista histórico de que as classes dominantes e subalternas nascem "no terreno originário de [sua] função essencial no mundo da produção econômica" (GRAMSCI, 2000a, p. 15), Gramsci ressalta que a atuação dessas classes, mediadas por seus intelectuais orgânicos, transcende a dimensão diretamente produtiva e se espraia pela totalidade do ser social, produzindo, reproduzindo ou transformando a produção da vida.

As classes dominantes no capitalismo caracterizam-se pela unidade mantida pelo controle do poder político e da propriedade material e imaterial dos meios de produção da riqueza socialmente gerada. Seu poder político se manifesta de dois modos, como domínio e como direção intelectual e moral. A burguesia, classe dominante e dirigente, exerce o seu poder de classe diretamente, por intermédio de ações desenvolvidas pelos seus variados aparelhos privados de hegemonia na sociedade civil e, indiretamente, por intermédio de ações desenvolvidas na aparelhagem estatal, materializadas nas leis e nas políticas governamentais. Especialmente nas sociedades de tipo ocidental, a burguesia, sem desprezar o uso da força como estratégia de dominação, tende a utilizar, de modo mais orgânico, estratégias de direção intelectual e moral que contribuem para consolidar a hegemonia política e cultural por ela conquistada.

Preocupado sobremodo com as possibilidades históricas de emancipação das classes subalternas da dominação burguesa, Gramsci enfatizou, em suas reflexões, a necessidade do entrelaçamento das dimensões cultural e política na sua formação. Para ele, o materialismo histórico ou a filosofia da práxis se constitui no plano intelectual em expressão das classes subalternas e se consubstancia em ferramenta teórica apropriada para que realize sua autoaprendizagem sobre a natureza das relações sociais em que vive. A filosofia da práxis se presta também para alicerçar as atuações organizativas com vistas à superação da exploração e da dominação a que são submetidas as classes subalternas no capitalismo.

Para Gramsci, portanto, as classes subalternas "por definição, não são unificadas e não podem se unificar enquanto não puderem se tornar 'Estado' [...]" (GRAMSCI, 2002, p. 139). Inversamente, porém, as classes dominantes caracterizam-se pela unidade mantida pelo controle do poder político e da propriedade material e imaterial dos meios de produção da riqueza socialmente gerada.

A construção da unidade das classes subalternas requer a tomada de consciência da exploração e da dominação a que elas se encontram submetidas e a organização de uma vontade coletiva para sua superação. Nesse sentido, ele observou que

É através da crítica à civilização capitalista que se forma ou se está formando a consciência unitária do proletariado: e crítica 
quer dizer cultura, e não evolução espontânea e natural. Crítica quer dizer precisamente aquela consciência do eu que Novalis definia como meta da cultura. Um eu que se opõe aos outros, que se diferencia, e que tendo criado para si mesmo uma finalidade, julga os fatos e os eventos não só em si e para si, mas também como valores de propulsão ou de repulsão. Conhecer a si mesmo significa ser si mesmo, ser o senhor de si mesmo, diferenciar-se, elevar-se acima do caos, ser um elemento de ordem, mas da própria ordem e da própria disciplina diante de um ideal. E isso não poderá ser obtido se também não se conhecem os outros, a história deles, a sucessão dos esforços que fizeram para ser o que são, para criar a civilização que criaram e que nós queremos substituir pela nossa (GRAMSCI, 2004, p. 60).

A consciência de classe do proletariado se constrói na reflexão e na ação, em meio ao enfrentamento de problemas concretos resultantes da estrutura e da dinâmica capitalistas. A consciência de ser desenvolve a vontade política de tornar-se. Do ponto de vista marxista, vontade "significa consciência da finalidade", ou seja, "significa [ter] a noção exata do próprio poder e dos meios para expressá-lo na ação” (GRAMSCI, 2004, p. 163-164).

Gramsci salienta, ainda, que a construção da vontade coletiva é um processo longo, caracterizado por graus diferenciados de consciência política coletiva, vivenciados nos diferentes momentos de relações das forças sociais em luta, em cada formação social concreta e em cada conjuntura histórica. "O primeiro e mais elementar é o econômicocorporativo", onde "sente-se a unidade homogênea do grupo profissional e o dever de organizá-la, mas não ainda a unidade do grupo social mais amplo" (GRAMSCI, 2000b, p. 41). No segundo momento, os grupos específicos atingem "a consciência da solidariedade de interesses entre todos os membros do grupo social, mas ainda no campo meramente econômico" (GRAMSCI, 2000b, p. 41). Nesse momento, questiona-se a igualdade político-jurídica com os grupos dominantes, reivindica-se o direito de participar da legislação e da administração e mesmo de modificá-las, mas nos marcos do capitalismo. Num terceiro momento, ultrapassa-se o plano econômico-corporativo e atinge-se o plano ético-político, quando as classes subalternas procuram consolidar sua unidade econômica, política e cultural. As classes subordinadas, ao perceberem com nitidez a natureza de classe do Estado capitalista, tendem a organizadamente construir uma vontade nacional popular com vistas à efetivação de uma reforma intelectual e moral de longo prazo (GRAMSCI, 2000b).

Embora historicamente, de um modo geral, a classe dominante obtenha êxito nas suas estratégias de exploração e de dominação, ela enfrenta também crises de hegemonia, que ameaçam a sua unidade de classe. Tais crises de hegemonia se verificam quando essa classe fracassa "em algum grande empreendimento político para o qual pediu ou impôs pela força o consenso das grandes massas" (GRAMSCI, 2000b, p. 60) ou quando "amplas massas [passam] subitamente da passividade política para uma certa atividade e apresentam reivindicações que, em seu conjunto desorganizado, constituem uma revolução" (GRAMSCI, 2000, p. 60).

Para permanecer dirigente, a classe burguesa põe-se a si mesma como um organismo em contínuo movimento, atualizando frequentemente suas estratégias de convencimento de toda a sociedade, chegando mesmo a fazer, para tal fim, sacrifícios de 
ordem econômico-corporativos que possam satisfazer parcialmente interesses e tendências dos grupos sob a sua direção.

Mesmo que tenham sido significativas as contribuições gramscianas em relação ao papel desempenhado pela atividade humana na formação de uma classe e, mais especificamente, na unificação da classe trabalhadora, enquanto classe para $\mathrm{si}^{5}$, foram decisivas, nessa perspectiva, as contribuições de Thompson no que tange ao esforço de sistematização teórica sobre a natureza desse fenômeno histórico que corroboram, explicitam e até mesmo ampliam os enunciados do pensador italiano.

Para Thompson a classe faz-se. É um processo histórico. É um processo que se deve tanto à ação humana como aos seus determinantes, um fenômeno histórico que "unifica uma série de acontecimentos díspares e aparentemente desconectados, tanto na matéria prima da experiência como na consciência" (THOMPSON, 1987, p. 9). A classe é também uma relação e, como tal, "precisa estar sempre encarnada em pessoas e contextos reais" (THOMPSON, 1987, p. 10). Daí ele sentenciar:

classe, na tradição marxista é (ou deve ser) uma categoria histórica descritiva de pessoas numa relação no decurso do tempo e das maneiras pelas quais se tornam conscientes de suas relações, como se separam, unem, entram em conflito, formam instituições e transmitem valores de modo classista (THOMPSON, 2001, p. 260) .

Nesses termos, a classe é tanto uma formação social como cultural que não pode ser definida abstrata ou isoladamente, mas apenas em termos de relações recíprocas com as outras classes.

Como categoria analítica, a classe é inseparável da noção de luta de classes. Aliás, para Thompson, por ser um conceito histórico que implica em processo e por ser mais universal, o conceito de luta de classes é prioritário. A luta de classes é um conceito anterior ao de classe. Na verdade, a classe surge da luta.

O processo de formação de uma classe integra simultaneamente a experiência e a consciência de classe. A experiência de classe é determinada, em grande parte, pelas relações de produção em que os homens nasceram ou ingressaram involuntariamente e a consciência de classe resulta "da forma como essas experiências são tratadas em termos culturais: encarnadas em tradições, sistemas de valores, ideias e formas institucionais" (THOMPSON, 1987, p. 10.). Thompson reforça esta ideia, afirmando sinteticamente que "formações de classe [...] surgem no cruzamento da determinação e da autoatividade". (THOMPSON, 1981, p. 121). Nessa perspectiva de análise, classe e consciência de classe são sempre o último e não o primeiro degrau de um processo histórico real. Para ele,

a formação de classe [não pode] ser independente de determinações objetivas, nem [...] a classe [pode ser] definida como simples fenômeno cultural. [...] Nenhum exame das determinações objetivas e, mais do que nunca, nenhum modelo eventualmente teorizado podem levar à equação simples de uma classe como consciência de classe. A classe se delineia segundo o modo como os homens e mulheres vivem suas relações de produção e segundo a experiência de suas situações determinadas, no interior do "conjunto das suas relações sociais", com a cultura e as expectativas a eles transmitidas e com base no modo pelo qual se valeram dessas experiências em nível cultural (THOMPSON, 2001, p. 277, grifos do autor). 
O conceito de experiência ocupa papel central na reflexão thompsiana sobre cultura e classe social. Mattos (2012) observou que, nos debates que se seguiram à publicação do livro A miséria da teoria, Thompson (1981) explicou que experiência "incluía-se entre aqueles "conceitos de junção" que ele e Raymond Williams tentavam desenvolver para entender as sociedades. Nesse caso, a junção se daria entre cultura e não cultura, a metade dentro do ser social, a metade dentro da consciência social" (THOMPSON, 1984, p. 314 apud MATTOS, 2012, p. 85). Tentando definir melhor a dupla face do conceito, denominou-a de experiência vivida e experiência percebida.

Em todos os seus estudos sobre classe, para salientar a mediação da "agência" da classe, Thompson procurou apresentar, na relação complexificada entre a determinação das relações sociais de produção e a dimensão cultural da consciência de classe, a mediação da experiência em sua dupla dimensão (MATTOS, 2012). Para ele, pela experiência "a estrutura é transmutada em processo e o sujeito é reinserido na história" (THOMPSON, 1981, p. 188). De forma muito aguda, ele observou que o que se altera quando ocorre uma mudança "no modo de produção e nas relações produtivas é a experiência de homens e mulheres existentes" (THOMPSON, 2001, p. 260). Com essa compreensão, Thompson, ao mesmo tempo em que reafirma, com o materialismo, a determinação material no modo de pensar, sentir e agir humanos, recupera o protagonismo da ação humana no desenrolar dos processos históricos.

Embora reconhecesse a importância da experiência na formação dos sujeitos singulares e coletivos, Thompson tinha clareza de que verdade e experiência não se confundem. A verdade é mais nuançada que a experiência. A experiência surge espontaneamente nas relações sociais, exigindo reflexões, "[...] porque homens e mulheres (...) são racionais e refletem sobre o que acontece a eles e ao mundo" (THOMPSON, 1981, p. 16), mas ela se configura como "uma parte da matéria-prima oferecida aos processos do discurso científico da demonstração" (THOMPSON, 1981, p. 16). E esclarece:

[...] ocorrem mudanças no ser social que dão origem a uma experiência modificada; e essa experiência é determinante, no sentido de que exerce pressões sobre a consciência social existente, propõe novas questões e proporciona grande parte do material sobre o qual se desenvolvem os exercícios intelectuais mais elaborados (THOMPSON, 1981, 16).

Thompson observou ainda quanto ao elo indissociável experiência, consciência social e classe que a experiência "adquire feições classistas, na vida social e na consciência, no consenso, na resistência e nas escolhas de homens e mulheres" (THOMPSON, 2001, p. 260). Os nexos encontrados por este autor entre classe, experiência e consciência social contribuem significativamente para uma compreensão mais realista dos processos de dominação social e cultural nas sociedades contemporâneas.

As noções de hegemonia, de formação de classe e experiência tomadas de empréstimo, respectivamente, de Gramsci e de Thompson se consubstanciaram em alicerces fundamentais no desenvolvimento da teoria do materialismo cultural de Williams. Contribuiu ainda significativamente nesse sentido seu olhar crítico sobre a noção de totalidade social, elemento fundante do materialismo histórico.

Refletindo sobre a noção de totalidade social na construção de sua teoria da cultura, Williams observou que a noção de totalidade pode facilmente se esvaziar da proposição original marxista, se apenas se restringir ao caráter de complexidade do conjunto das práticas sociais. Para evitar esse esvaziamento, ele propôs relacionar a noção de totalidade 
social à noção de intencionalidade das ações humanas e assim resgatar o caráter de classe das práticas sociais e culturais contemporâneas. Para Williams,

\begin{abstract}
A noção de intenção recupera [...] a ênfase central, pois, embora seja verdade que qualquer sociedade é um todo complexo de [...] práticas, também é verdade que toda sociedade tem uma organização e uma estrutura específicas, e que os princípios dessa organização e estrutura podem ser vistos como diretamente relacionados a certas intenções sociais, pelas quais definimos a sociedade, intenções que, em toda a nossa experiência, têm sido regidas por uma classe particular. [...] [As] leis, constituições, teorias e ideologias que são tão frequentemente defendidas como naturais ou como tendo validade ou significância universal devem ser vistas como simplesmente expressando e ratificando a dominação de uma classe particular (WILLIAMS, 2011, p.50-51).
\end{abstract}

A dialeticidade resgatada por essa associação entre totalidade social e intencionalidade da ação humana retira das análises das práticas sociais e culturais contemporâneas qualquer vestígio espontaneísta ou relativista. As práticas culturais demonstram, dessa forma, que a intencionalidade humana de dominação vai além das formas coercitivas; elas atuam de modo a viabilizar a incorporação pelo conjunto da sociedade dos fundamentos e práticas dos projetos sociopolíticos das classes dominantes, sedimentando a hegemonia de classe.

\title{
Hegemonia segundo Gramsci, Thompson e Williams
}

Embora Gramsci já estivesse atento para as questões pertinentes à hegemonia cultural e política antes da sua prisão, foi nesse período que ele desenvolveu de forma mais orgânica suas ideias sobre a relação entre cultura, política e hegemonia. Este conceito procura dar conta de explicar as formas de dominação de classe próprias das sociedades capitalistas ${ }^{7}$, em especial nas sociedades capitalistas de tipo ocidental ou em processo de ocidentalização. Ou seja, das formações sociais concretas urbano-industriais que realizaram, em menor ou maior grau, uma socialização da participação política a partir da segunda metade do século XIX, ocasionando uma mudança qualitativa na estruturação e dinâmica das relações de poder.

Em Gramsci, a reflexão sobre hegemonia se insere nas suas reflexões sobre a ampliação das funções ético-políticas do Estado no capitalismo monopolista. Nesse estágio do capitalismo, o Estado adquire uma nova materialidade, representada pela complexificação da burocracia civil e militar da aparelhagem estatal ou do Estado stricto sensu e na crescente expansão dos aparelhos privados de hegemonia na sociedade civil. $\mathrm{O}$ Estado redefine suas funções, acrescentando às tarefas de comando, governo e domínio a hegemonia civil, ou seja, a direção cultural e política, intelectual e moral das classes dominadas, por meio da sua adesão espontânea ao projeto político e social da classe dominante e dirigente ${ }^{8}$ (NEVES, 2005).

Nesse contexto histórico de alargamento da participação política, portanto, o Estado assumiu incisivamente o seu papel educador ${ }^{9}$, incumbindo-se mais organicamente de

criar novos e mais elevados tipos de civilização, de adequar a 'civilização' e a moralidade das mais amplas massas populares às necessidades do contínuo desenvolvimento do aparelho econômico de 
produção e, portanto, de elaborar também fisicamente tipos novos de humanidades (Gramsci, 2000b, p. 23).

Esse olhar sobre a nova estrutura e dinâmica das sociedades contemporâneas e, mais especificamente, sobre a ampliação do Estado o levou a inferir que "toda relação de 'hegemonia' é necessariamente uma relação pedagógica, que se verifica não apenas no interior de uma nação, entre as diversas forças que a compõem" e também "[...] entre conjuntos de civilizações nacionais e continentais"10 (GRAMSCI, 1999, p. 399). Na condição de educador, o Estado capitalista desenvolve uma pedagogia da hegemonia que redefine e atualiza em cada conjuntura política e social suas estratégias, com vistas a manter viva a dominação de classe. As ideias, valores e práticas hegemônicas são viabilizadas por intelectuais individuais e coletivos orgânicos de projeto político das classes dirigentes.

O exercício "normal" da hegemonia se caracteriza pela combinação da força e do consenso, que se equilibram de modo variado, desde que a força não suplante em muito o consenso ${ }^{11}$. Esse exercício requer que a força pareça apoiada no consenso da maioria, viabilizado pela capilaridade das ações dos mais diversos aparelhos culturais, entre eles escola, igreja, mídia, e por diferentes tipos de organismos políticos. Gramsci destaca ainda que o êxito de uma certa hegemonia política e cultural pressupõe que sejam levados em consideração os interesses e as tendências dos grupos sobre os quais a hegemonia é exercida, circunscritos aos limites impostos pela necessidade de conservação das relações sociais vigentes.

Entretanto, Gramsci ressalta que o caráter contraditório das formações sociais capitalistas possibilita, simultaneamente, a formulação de ideias, a difusão de valores e o desenvolvimento de ações contra-hegemônicas. Forças políticas oposicionistas empreendem no Estado stricto sensu e, majoritariamente, nos diversos aparelhos privados de hegemonia culturais e políticos da sociedade civil uma pedagogia da contra-hegemonia, comprometida com a conscientização política das classes dominadas no sentido de superar as relações de exploração e de dominação a que estão submetidas (NEVES, 2005). O conteúdo, a forma e o alcance dessas ações dependem do nível de consciência política coletiva alcançado pelas forças contra-hegemônicas em cada conjuntura histórica.

As ideias gramscianas sobre hegemonia inspiraram os estudos de Thompson sobre a constituição da classe operária inglesa e, de modo mais abrangente, sobre as peculiaridades da dominação de classe na Inglaterra. Essas ideias fizeram com que Thompson pudesse constatar que "o poder de classe poderia agora ser visto não mais como uma mera ditadura mal disfarçada, mas em formas muito mais sutis, penetrantes e, consequentemente, compulsivas" (THOMPSON, 2001, p. 148).

Com base nesse novo olhar, Thompson constatou que só muito raramente, e por pouco tempo, "uma classe dominante exerce sem mediações sua autoridade por meio da força militar e econômica direta" (THOMPSON, 2001, p. 239). De um modo geral, o conteúdo e a forma da dominação são assimilados e difundidos pelos subordinados, desde a mais tenra infância, como naturalmente constituídos, pois as pessoas vêm ao mundo em uma sociedade cujas formas e relações parecem fixas e imutáveis. Embora assegurasse que "o 'senso comum' de uma época [se fazia] saturado com uma ensurdecedora propaganda do status quo" (THOMPSON, 2001, p. 239), advertia que simplesmente o fato de existir se constituiria no elemento mais forte para a reprodução das relações sociais vigentes. Tais convicções o levaram a afirmar, analisando as relações de poder na Inglaterra do século XVIII, que o exercício do poder de classe à época repousava, em parte, na encenação da hegemonia cultural, uma vez que a hegemonia da gentry e da 
aristocracia se materializava principalmente nos rituais das cortes de justiça.

Assim como Gramsci, Thompson também apontava para a possibilidade de uma classe subordinada se preparar para o exercício da hegemonia, exercendo influência sobre a vida intelectual e moral de uma nação, por intermédio, entre outros, de suas instituições educacionais e do controle dos órgãos de governo local. No entanto, advertia que o máximo que conseguia antever para as classes subalternas era uma hegemonia embrionária exercida em áreas muito limitadas da vida nacional.

Sem dúvida, o conceito de hegemonia ocupa um espaço privilegiado nas reflexões thompsianas sobre a formação das classes. Entretanto, é com Williams que o conceito gramsciano de hegemonia ${ }^{12}$ recebe novas e importantes determinações. Esse autor se preocupou, de forma mais sistemática, em explicar a especificidade da hegemonia cultural. Embora reconhecesse que a dominação essencial de uma determinada classe na sociedade se efetivasse por intermédio de relações de poder e de propriedade, ele reconheceu que esta dominação era exercida também, inevitavelmente, pela "cultura do vivido", pela

[...] saturação do hábito, da experiência, dos modos de ser, sendo continuamente renovada em todas as etapas da vida, desde a infância, sob pressões definidas e no interior de significados definidos, de tal forma que o que as pessoas vêm a pensar e a sentir é, em larga medida, uma reprodução de uma ordem social profundamente arraigada a que as pessoas podem até pensar que, de algum modo, se opõem, e a que, muitas vezes, se opõem de fato (WILLIAMS, 1975, p. 74 apud CEVASCO, 2001, p. 127).

Williams admitiu que, ao especificar a diferença entre dominação de classe por domínio e por hegemonia, Gramsci ofereceu elementos decisivos para o desenvolvimento de sua teoria cultural. E, no esforço de construção dessa teoria, Williams, realizando uma superação dialética dos ensinamentos do pensador sardo, esclarece e acrescenta, de modo sistemático, outras determinações ao conceito.

Ele verificou, por exemplo, que nas formações sociais concretas a dominação por domínio se expressa "em formas diretamente políticas e em tempos de crise, pela coação direta ou efetiva" (WILLIAMS, 1979, p. 111). Observou, também, que em situações de normalidade vigora "uma complexa combinação de forças políticas, sociais e culturais" (WILLIAMS, 1979, p. 111), que inclui domínio e hegemonia, que tem nas forças sociais e culturais ativas seus elementos necessários.

Ressaltou, ainda, que "a verdadeira condição de hegemonia supõe a autoidentificação efetiva com as formas hegemônicas" (WILLIAMS, 1979, p. 121), ou seja, uma socialização específica e internalizada, de caráter positivo, ou mesmo um reconhecimento resignado do inevitável e necessário da manutenção da sociedade de classes. A hegemonia, portanto, supõe uma incorporação efetiva, na prática, da condição de subalternidade.

O conceito gramsciano de hegemonia inclui e ultrapassa os conceitos de cultura e de ideologia. Ele introduz "o reconhecimento necessário do domínio e da subordinação" nas sociedades de classe (WILLIAMS, 1979, p. 112). A cultura, nessas sociedades, é um modo de vida, mas é também um modo de luta. Esse conceito possibilita ainda compreender que o processo de dominação de classes envolve um sistema de significados e valores, mas envolve, concomitantemente, todo um conjunto de "práticas e expectativas sobre a totalidade da vida". A hegemonia se configura, nessa perspectiva, como um "sistema vivido de significados e valores - constitutivo e constituidor - que, ao serem 
experimentados como práticas, parecem confirmar-se reciprocamente" (WILLIAMS, 1979, p. 113). Para consolidar um processo de dominação de classe, portanto, "decisivo não é apenas o sistema consciente de ideias e crenças, mas todo o processo social vivido, organizado praticamente por significados e valores específicos e dominantes" (WILLIAMS, 1979, p. 112).

"Uma hegemonia vivida é sempre um processo", ou seja, "um complexo realizado de experiências, relações e atividades, com pressões e limites específicos e mutáveis", que deve "ser renovada continuamente, recriada, defendida e modificada" por sofrer também "uma resistência continuada, limitada, alterada, desafiada" por pressões alternativas e/ou opostas (WILLIAMS, 1979, p. 115). Esses complexos elementos da realidade vivida permitem acrescentar ao conceito de hegemonia os conceitos de contra-hegemonia e de hegemonia alternativa.

A hegemonia é sempre um processo ativo, relativamente organizado e interligado de valores, práticas e ideias incorporados "numa cultura significativa e numa ordem social efetiva" (WILLIAMS, 1979, p. 118). Williams enfatiza que o processo de incorporação abstraído na sociologia ortodoxa como "socialização" é, na prática e em qualquer sociedade real, um tipo específico de incorporação.

Qualquer processo de socialização inclui, é claro, coisas que todos os seres humanos têm de aprender, mas qualquer processo específico une esse aprendizado necessário a uma variação selecionada de significados, valores e práticas, que, na intensidade mesma de sua associação com o aprendizado necessário, constitui a base real do hegemônico (WILLIAMS, 1979, p. 120).

O processo de incorporação se viabiliza por intermédio de três aspectos distintos do processo cultural: as tradições, as instituições e as formações (WILLIAMS, 1979). A tradição não é uma prática cultural de sobrevivência do passado, como é majoritariamente concebida. É um aspecto do passado, selecionado pelos dominantes, para manter a dominação presente. Segundo Williams, tradição "é na prática a expressão mais evidente das pressões e limites dominantes e hegemônicos" (WILLIAMS, 1979, p. 118). Em suma, ela é "um processo deliberadamente seletivo que oferece uma ratificação histórica e cultural de uma ordem contemporânea", no interesse da dominação de uma classe específica (WILLIAMS, 1979, p. 119).

As instituições formais têm uma influência profunda sobre o processo social ativo e, mais especificamente, nos processos incorporativos. A família, as escolas, as igrejas, as comunidades, os locais específicos de trabalho e comunicações são instituições incorporativas de destaque. Williams ressalta, porém, que o somatório dessas instituições não converte automaticamente em uma hegemonia orgânica. Pelo contrário, exatamente por ser o processo hegemônico complexo, ele é permeado por contradições e conflitos não solucionados.

As formações, por sua vez, são "movimentos e tendências efetivos, na vida intelectual e artística que têm influência significativa e por vezes decisiva no desenvolvimento ativo de uma cultura, e que têm uma relação variável, e com frequência oblíqua, com instituições formais" (WILLIAMS, 1979, p. 120). As formações desempenham um papel mais importante nas sociedades complexas e desenvolvidas. Elas se apresentam na realidade concreta como formações dominantes, residuais e emergentes. As formações dominantes são aquelas que se sobressaem, nas diferentes conjunturas históricas, na sedimentação de uma hegemonia. As formações residuais foram desenvolvidas no passado, mas atuam como elementos efetivos do presente. $\mathrm{Na}$ análise das formações residuais é preciso distinguir entre aquelas que podem ter, no tempo presente, uma relação alternativa ou mesmo oposta com a cultura dominante daquela que foi 
incorporada, em grande parte ou totalmente, pela cultura dominante. Já as formações emergentes se caracterizam pela criação de novos significados, novos valores, novas práticas, novas relações e tipos de relação em contraposição ao processo cultural e social dominante. Na realidade concreta, no entanto, é muito difícil distinguir entre os que são realmente elementos de uma fase nova da cultura dominante dos que são alternativos ou opostos $^{13}$ a essa cultura.

A apreensão do caráter complexo e contraditório das práticas incorporativas permitiu que Williams se encaminhasse para a constatação de que a hegemonia política e cultural, embora dominante, não pode ser total ou exclusiva (WILLIAMS, 1979). Para ele, o processo ativo da hegemonia não deve ser visto como uma mera transmissão do domínio. "Pelo contrário, qualquer processo hegemônico deve ser especialmente alerta e sensível" a processos alternativos (diferentes, mas dentro da ordem) e opositores (contra a ordem) que lhe questionam ou ameaçam o domínio (WILLIAMS, 1979, p.116). Daí o processo cultural não se constituir simplesmente um processo "adaptativo, extensivo e incorporativo" da cultura hegemônica, mas um processo perpassado "por rompimentos autênticos dentro e além dele, em condições sociais específicas" (WILLIAMS, 1979, p. 117).

Essa possibilidade de rompimento autêntico com os processos hegemônicos estimulou suas reflexões sobre os caminhos a serem trilhados na construção da contrahegemonia. Suas reflexões sobre a natureza das práticas culturais nas sociedades capitalistas contemporâneas o habilitaram a incluir as manifestações culturais entre as batalhas necessárias para a conquista da democracia e da vitória econômica da classe trabalhadora organizada. Nesse sentido, Williams reforça que "o sistema de significados e valores que a sociedade capitalista gera tem que ser derrotado no geral e no detalhe através de um trabalho intelectual e educacional contínuo" (WILLIAMS, 1975, p. 75-6 apud CEVASCO, 2001, p. 137), que ele denominou de longa revolução ${ }^{14}$.

Ele registrou ainda que "a ênfase, dada por Gramsci, na criação de uma hegemonia alternativa pela conexão prática de numerosas e diferentes formas de lutas, inclusive as que não são facilmente identificáveis como "políticas' e 'econômicas"' [...], contribui para a formação, em sociedades desenvolvidas, de um "senso muito mais profundo e ativo da atividade revolucionária" (WILLIAMS, 1979, p. 114). Para a construção desse senso mais profundo e ativo da atividade revolucionária, ele acreditava que os socialistas deveriam

[...] aprender e ensinar uns aos outros as conexões que existem entre uma formação política e uma econômica, e, talvez, o mais difícil, uma formação educacional e uma de sentimentos e de relações que são nossos recursos mais imediatos em qualquer forma de luta (WILLIAMS, 1975, p. 75-6 apud CEVASCO, 2001, p. 137).

\section{Considerações finais}

As reflexões de Gramsci, Thompson e Williams sobre os conceitos de estrutura, superestrutura, classe e hegemonia na sua relação com a cultura, nos marcos do materialismo histórico, trazem contribuições importantes para o entendimento do papel social e da natureza da educação na atualidade. Tais reflexões levam à reconsideração da maneira de tratar a relação entre educação e sociedade, educação e produção e educação e política nos dias de hoje.

O grau de complexidade das formações capitalistas contemporâneas permite observar, com maior clareza, que a ciência e a tecnologia perpassam o conjunto das atividades humanas. Nessa perspectiva, as descobertas científicas e as inovações 
tecnológicas desta nova fase do capitalismo monopolista se constituem em força produtiva fundamental para a produção da vida. Essa abordagem, ao ampliar o entendimento da relação entre produção e educação, permite que seja apreendida com mais nitidez a natureza mediata da relação trabalho e educação nas sociedades contemporâneas e nos aproxima da concepção marxiana de trabalho como atividade humana, como impulso de criação. A introdução incessante de inovações tecnológicas na produção da vida, como característica do modo de produção capitalista, gera sempre mudanças de intensidade e de qualidade no modo de vida que, por sua vez, exige do homem como sujeito e como produtor da existência a aprendizagem de novos conhecimentos e de novos comportamentos.

As reformas educacionais efetivadas neste início de novo século foram impulsionadas, em boa parte, pelas consequências práticas da difusão acelerada das novas tecnologias de informação e comunicação na sociedade como um todo, que vem transformando o modo de ser e de viver, cada vez mais racionalizado. A dimensão simbólica no capitalismo contemporâneo ganha uma centralidade que não existia em outros momentos históricos, fazendo crer que se está diante da emergência de um novo tipo de formação social.

Ao mesmo tempo, as análises desses três autores sobre a natureza de classe das formações sociais capitalistas oferecem outras ferramentas também importantes para o entendimento das determinações econômicas, políticas e culturais das reformas educacionais na atualidade. A produção da vida nessas formações se processa de acordo com as necessidades de exploração e de dominação das classes hegemônicas e do grau de organização dos explorados e dominados na resistência a essa dominação. Esse entendimento sobre a natureza de classe das formações sociais capitalistas ajuda a entender que a escola, como espaço estratégico da produção da vida no capitalismo contemporâneo, organiza suas atividades político-pedagógicas, majoritariamente, de acordo com as ideias, valores e práticas necessárias à reprodução da visão de mundo e do projeto político e cultural das classes dominantes.

A importância estratégica da educação é evidenciada por esses autores quando observam a dimensão pedagógica da formação de classe. A formação da consciência social é um ato educativo que se dá por intermédio da convivência social geral e também pela trajetória de escolarização.

A dominação de classe que perpassa a organização escolar nas sociedades capitalistas tem sido reforçada no início deste século por dois fenômenos concomitantes: a mundialização das relações sociais capitalistas e a mundialização da educação escolar. Por sua vez, a fragilidade dos projetos societais e educacionais opositores e da organização popular pós Guerra Fria tem favorecido a consolidação das diretrizes e práticas do bloco neoliberal no poder. As classes exploradas e dominadas cada vez mais incorporam como seus os modos de ser e de viver dos dominantes, acatando-os como os únicos possíveis e desejáveis. As classes trabalhadoras são educadas pelos mais variados aparelhos culturais (família, igreja, escola, mídia) e políticos (partidos, sindicatos, movimentos sociais, institutos e fundações empresariais e organizações não-governamentais internacionais e nacionais) para colaborar na conservação da ordem social vigente.

Ao destacar que no capitalismo a intencionalidade da ação humana é perpassada por interesses de classe, os três autores, ao mesmo tempo em que resgatam a importância da dimensão intelectual da organização da cultura no mundo contemporâneo, dirigem sua atenção para as estratégias de construção e consolidação da hegemonia política e cultural, estratégia de uma nova pedagogia da hegemonia que envolve a educação escolar, mas não se reduz a ela. 
Os três autores observaram também que a eficácia da hegemonia requer uma atualização constante de estratégias pedagógicas. O realce atribuído à dimensão cultural nas sociedades contemporâneas tem sido, em grande parte, uma tentativa sempre renovada de manutenção da dominação pelo consentimento. Ao mesmo tempo, a reprodução das relações sociais capitalistas passam a requerer, cada vez mais, o desenvolvimento do "capital humano", do "capital social" e do "capital cultural", traduzidos como a necessidade de qualificação de uma mão de obra sempre mais produtiva e competitiva; a difusão de uma participação política voltada para conciliação de antagonismos de classe; o resgate seletivo das tradições culturais; e a assimilação de práticas culturais emergentes ao projeto cultural dominante.

As incursões teóricas realizadas por esses autores, sem dúvida alguma, fornecem aos educadores brasileiros pistas interessantes para o enriquecimento da sua compreensão quanto à natureza das políticas educacionais implementadas desde o final do século anterior e também para entender o sentido da sua prática pedagógica.

\section{Referências}

CEVASCO, Maria Elisa. Para ler Raymond Williams. São Paulo: Paz e Terra, 2001.

GRAMSCI, Antonio. Escritos políticos. Vol. 1. Rio de Janeiro: Civilização Brasileira, 2004.

. Cadernos do cárcere. v.1. Rio de Janeiro: Civilização Brasileira, 1999.

Cadernos do cárcere. v. 2. Rio de Janeiro: Civilização Brasileira, 2000a.

Cadernos do cárcere. v. 3. Rio de Janeiro: Civilização Brasileira, 2000b.

Cadernos do cárcere. v. 4. Rio de Janeiro: Civilização Brasileira, 2001.

Cadernos do cárcere. v. 5. Rio de Janeiro: Civilização Brasileira, 2002.

MARTINS, Ângela Maria Souza; NEVES, Lúcia Maria Wanderley. Materialismo histórico, cultura e educação: Gramsci, Thompson, Williams. Revista HISTEDBR (on line). Aprovado para publicação em 2013.

MATTOS, Marcelo Badaró. E.P. Thompson e a tradição de crítica ativa do materialismo histórico. Rio de Janeiro: Editora UFRJ, 2012.

NEVES, Lúcia Maria Wanderley. A nova pedagogia da hegemonia: estratégias do capital para educar o consenso. São Paulo: Xamã, 2005.

THOMPSON, E. P. A miséria da teoria ou um planetário de erros: uma crítica ao pensamento de Althusser. Rio de Janeiro: Zahar, 1981.

A formação da classe operária inglesa. v. 1. Rio de Janeiro: Paz e Terra, 1987.

As peculiaridades dos ingleses e outros artigos. Campinas, São Paulo: Editora Unicamp, 2001. 
Os românticos. Rio de Janeiro: Civilização Brasileira, 2002.

. Costumes em comum: estudos sobre a cultura popular tradicional. São Paulo: Companhia das Letras, 2005.

WILLIAMS, Raymond. Cultura e Sociedade. São Paulo: Companhia Editora Nacional, 1969.

. Marxismo e literatura. Rio de Janeiro: Zahar, 1979.

Cultura e materialismo. São Paulo: Editora Unesp, 2011.

Recebido em abril-2014

Aprovado em maio-2014

\begin{abstract}
Notas
${ }^{1}$ Professora Associada 4 da Universidade Federal do Estado do Rio de Janeiro

${ }^{2}$ Professora aposentada da UFPE, pesquisador visitante do Programa de Pós-Graduação em Educação da UFF

${ }^{3}$ Enquanto Gramsci e Thompson contribuíram de maneira indireta para a construção dessa teoria, Raymond Williams, dialogando com esses autores, dedicou-se a desenvolver sistematicamente uma teoria marxista de cultura, por ele denominada de materialismo cultural.

${ }^{4}$ Gramsci analisa o desdobramento e o rumo do capitalismo nos Estados Unidos. Mostra que houve uma transformação no capitalismo liberal centrado na figura do empreendedor individual e do mercado autorregulado para formas de capitalismo regulado. Surgia assim a cultura do americanismo, trazendo uma nova dinâmica para o capitalismo que enfatiza a racionalização da organização social e num novo tipo de hegemonia porque, de acordo com Gramsci, "na América, a racionalização determinou a necessidade de elaborar um novo tipo humano, adequado ao novo tipo de trabalho e de processo produtivo (...) [sendo] ainda [uma] fase de adaptação psicofísica à nova estrutura industrial” (GRAMSCI, 2001, p. 248).
\end{abstract}

5 Marx expressou a diferença entre a existência material da classe trabalhadora e a sua tomada de consciência, na luta de classes, através das expressões classe em si e classe para si (Badaró, 2012).

${ }^{6}$ Thompson reproduz esta ideia de maneiras variadas em diversas passagens de sua obra. No prefácio de $A$ formação da classe operária inglesa, por exemplo, diz: a classe "acontece quando alguns homens, como resultado de experiências comuns (...) sentem e articulam a identidade de seus interesses entre si, e contra outros homens cujos interesses diferem (e geralmente se opõem) dos seus" (THOMPSON, 1987, p. 10). Diz também em A miséria da teoria que "as classes surgem porque homens e mulheres, em relações produtivas determinadas, identificam seus interesses antagônicos e passam a lutar, a pensar, e a valorar em termos de classe: assim o processo de formação de classe é um processo de autoconfecção, embora sob condições que são "dadas” (THOMPSON, 1981, p. 121).

${ }^{7}$ Gramsci reconhece que ditadura e hegemonia, coerção e consenso são inerentes às relações de dominação desde o surgimento do Estado moderno. Partindo da análise de $O$ príncipe, observou que "Maquiavel examina sobretudo as questões de grande política: criação de novos Estados; conservação e defesa de estruturas orgânicas em seu conjunto; questões de ditadura e hegemonia em ampla escala,(...) em toda a área estatal" (GRAMSCI, 2000b, p. 22).

${ }^{8}$ Gramsci enunciou a ampliação do Estado nos seguintes termos: "Por enquanto, podem-se fixar dois grandes 'planos' superestruturais: o que pode ser chamado de 'sociedade civil', isto é, o conjunto de organismos designados vulgarmente como 'privados' e o da 'sociedade política ou Estado', planos que correspondem, respectivamente, à função de 'hegemonia' que o grupo dominante exerce em toda a sociedade 
e àquela de 'domínio direto' ou de comando, que se expressa no Estado e no governo 'jurídico" (GRAMSCI, 2000a, p. 20-21).

${ }^{9}$ Gramsci observou que o Estado moderno, "por substituir o bloco mecânico dos grupos sociais por uma subordinação destes à hegemonia ativa do grupo dominante e dirigente" (GRAMSCI, 2002, p. 139), redefine suas práticas tornando-se educador.

${ }^{10}$ Gramsci reconheceu a importância do pensamento de Lenin, no campo marxista, e de Benedetto Croce, no campo liberal, no desenvolvimento de suas ideias sobre a natureza da hegemonia no mundo contemporâneo.

${ }^{11}$ Nessa perspectiva, os aparelhos privados de hegemonia cultural e política da sociedade civil teriam como uma das suas funções legitimar, pelo convencimento, as ações de domínio direto ou de comando definidas pelo Estado stricto sensu.

${ }^{12}$ Em Marxismo e literatura (WILLIAMS, 1979), esse autor afirmou que "a definição tradicional de "hegemonia" é poder ou domínio político, especialmente nas relações entre Estados. O marxismo ampliou essa definição para as relações entre as classes sociais, especialmente as definições de uma classe dominante. "Hegemonia" adquiriu então outra significação na obra de Antonio Gramsci" (...). Muita coisa é ainda incerta no uso que Gramsci faz do conceito, mas sua obra é um dos pontos marcantes da teoria cultural marxista" (WILLIAMS, 1979, p. 111). Sobre a influência de Gramsci na sua elaboração teórica, Williams observou que era evidente que "estávamos diante de uma nova forma do estado corporativo" e de uma ênfase na cultura e que "a tentativa de se definir esta nova situação nos possibilitou rever partes importantes da tradição marxista, notadamente o trabalho de Gramsci com sua ênfase na hegemonia" (WILLIAMS, 1975, p. 74 apud CEVASCO, 2001, p. 127).

${ }^{13}$ Williams esclarece: "Há uma distinção teórica simples entre o alternativo e o opositor, isto é, entre alguém que meramente encontra um jeito diferente de viver e quer ser deixado só e alguém que encontra uma maneira diferente de viver e quer mudar a sociedade.(...) Frequentemente, contudo, a linha entre o alternativo e o opositor é na realidade, muito estreita" (WILLIAMS, 2011, p. 58).

${ }^{14}$ A concepção de longa revolução em Williams se aproxima da ideia gramsciana de revolução processual, na qual, em meio à construção de uma vontade nacional popular, deveria se realizar também uma reforma intelectual de moral da sociedade.

Recebido em julho/13

Aprovado em outubro/13 